\title{
FEASIBILITY AND TESTING OF A LIGHTWEIGHT, ENERGY EFFICIENT, ADDITIVE MANUFACTURED PNEUMATIC CONTROL VALVE
}

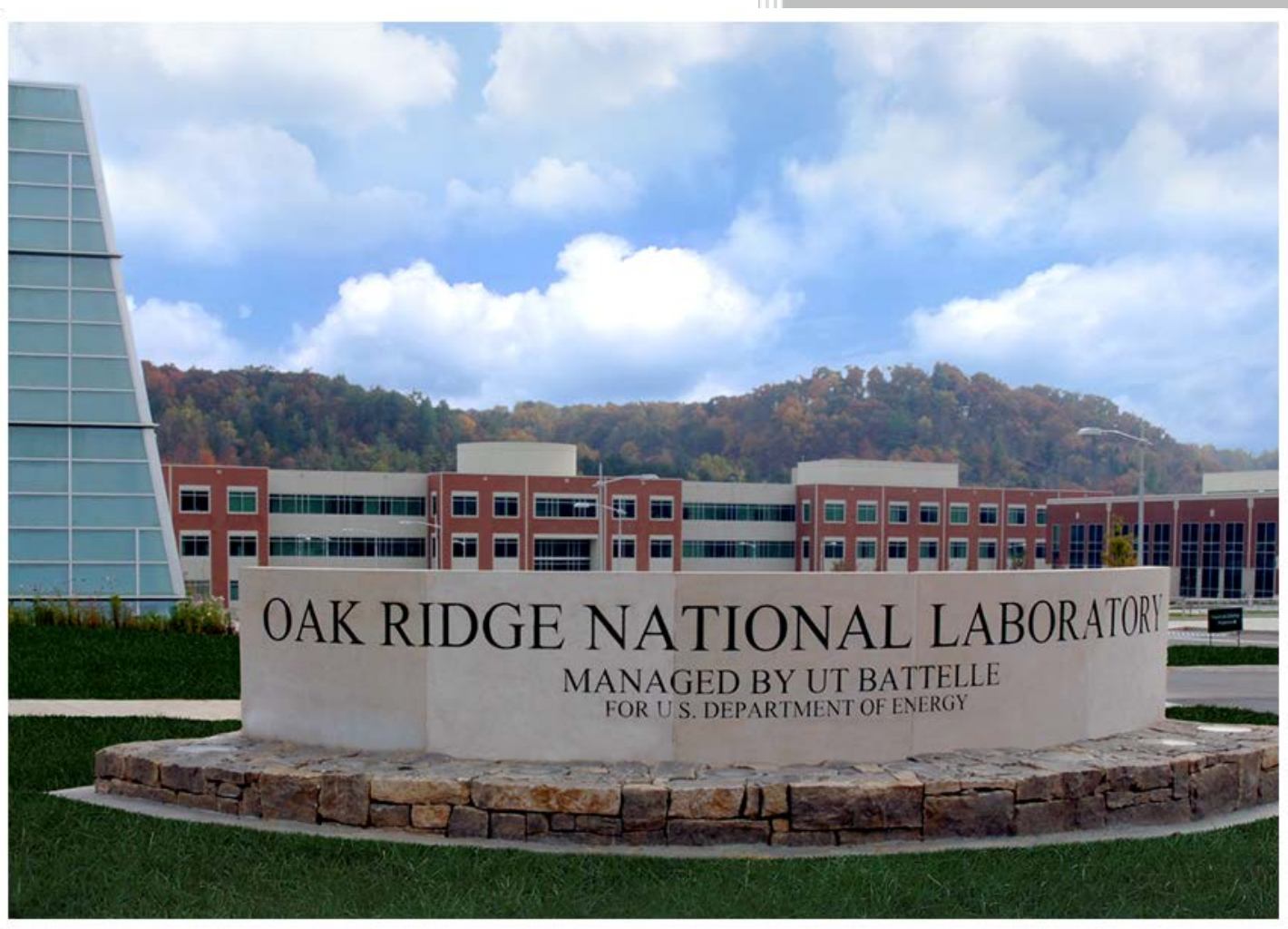

CRADA Final Report for CRADA number NFE-14-04912

Approved for public release; distribution is unlimited.
Lonnie J. Love

October 24, 2014 


\section{DOCUMENT AVAILABILITY}

Reports produced after January 1, 1996, are generally available free via US Department of Energy (DOE) SciTech Connect.

Website http://www.osti.gov/scitech/

Reports produced before January 1, 1996, may be purchased by members of the public from the following source:

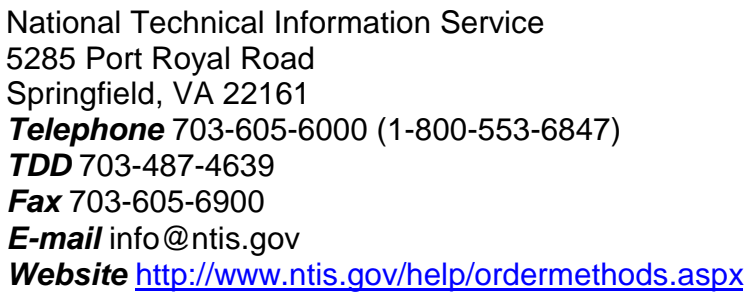

Reports are available to DOE employees, DOE contractors, Energy Technology Data Exchange representatives, and International Nuclear Information System representatives from the following source:

Office of Scientific and Technical Information

PO Box 62

Oak Ridge, TN 37831

Telephone 865-576-8401

Fax 865-576-5728

E-mail reports@osti.gov

Website http://www.osti.gov/contact.html

This report was prepared as an account of work sponsored by an agency of the United States Government. Neither the United States Government nor any agency thereof, nor any of their employees, makes any warranty, express or implied, or assumes any legal liability or responsibility for the accuracy, completeness, or usefulness of any information, apparatus, product, or process disclosed, or represents that its use would not infringe privately owned rights. Reference herein to any specific commercial product, process, or service by trade name, trademark, manufacturer, or otherwise, does not necessarily constitute or imply its endorsement, recommendation, or favoring by the United States Government or any agency thereof. The views and opinions of authors expressed herein do not necessarily state or reflect those of the United States Government or any agency thereof. 
ORNL/TM-2014/608

CRADA/NFE-14-04912

Energy and Transportation Science Division Advanced Manufacturing Office

\title{
FEASIBILITY AND TESTING OF A LIGHTWEIGHT, ENERGY EFFICIENT, ADDITIVE MANUFACTURED PNEUMATIC CONTROL VALVE
}

\author{
Authors \\ Lonnie J. Love \\ Ellen Mell, AeroValve, LLC \\ Date Published: \\ October 24, 2014 \\ Prepared by \\ OAK RIDGE NATIONAL LABORATORY \\ Oak Ridge, Tennessee 37831-6283 \\ managed by \\ UT-BATTELLE, LLC \\ for the \\ US DEPARTMENT OF ENERGY \\ under contract DE-AC05-00OR22725
}

Approved For Public Release 



\section{CONTENTS}

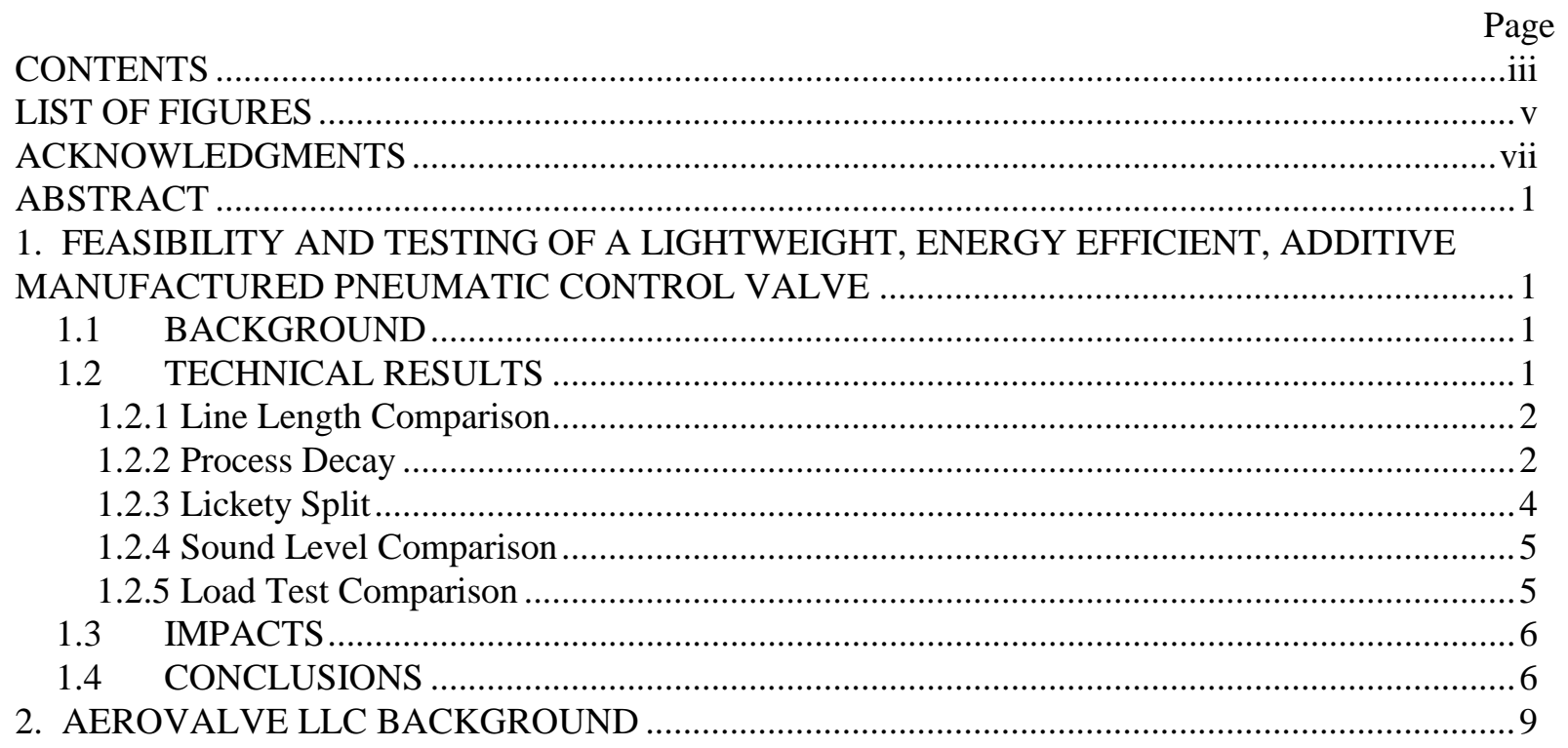





\section{LIST OF FIGURES}

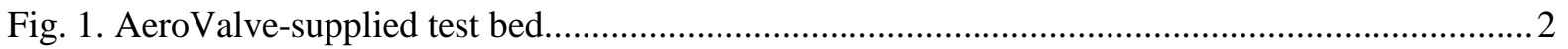

Fig. 2. Pressure decay with .75s \& 90/80 psi vs. tubing length. ........................................................... 3

Fig. 3. Pressure decay .75s mapped against all pressures and line lengths. ........................................... 3

Fig. 4. Pressure decay with 90/80 psi vs. time constants and line length............................................. 4

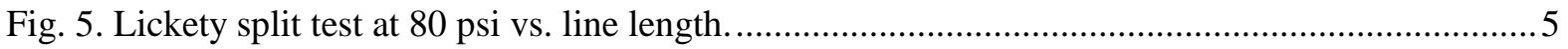

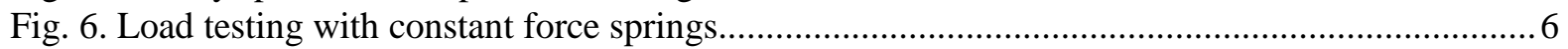





\section{ACKNOWLEDGMENTS}

This CRADA NFE-14-04912 was conducted as a Technical Collaboration project within the Oak Ridge National Laboratory (ORNL) Manufacturing Demonstration Facility (MDF) sponsored by the US Department of Energy Advanced Manufacturing Office (CPS Agreement Number 24761).

Opportunities for MDF technical collaborations are listed in the announcement "Manufacturing Demonstration Facility Technology Collaborations for US Manufacturers in Advanced Manufacturing and Materials Technologies” posted at http://web.ornl.gov/sci/manufacturing/docs/FBO-ORNL-MDF2013-2.pdf. The goal of technical collaborations is to engage industry partners to participate in shortterm, collaborative projects within the Manufacturing Demonstration Facility (MDF) to assess applicability and of new energy efficient manufacturing technologies. Research sponsored by the U.S. Department of Energy, Office of Energy Efficiency and Renewable Energy, Advanced Manufacturing Office, under contract DE-AC05-00OR22725 with UT-Battelle, LLC. 



\begin{abstract}
This Oak Ridge National Laboratory (ORNL) Manufacturing Development Facility (MDF) technical collaboration project was conducted in one phases as a CRADA with AeroValve, LLC. AeroValve's innovative pneumatic valve technology recycles compressed air through the valve body with each cycle of the valve, and was reported to reduce compressed air requirements by an average of $25 \%-30 \%$. This technology collaboration project between ORNL and AeroValve confirms the energy efficiency of valve performance. Measuring air consumption per work completed, the AeroValve was as much as $85 \%$ better than the commercial Festo valve.
\end{abstract}

\title{
1. FEASIBILITY AND TESTING OF A LIGHTWEIGHT, ENERGY EFFICIENT, ADDITIVE MANUFACTURED PNEUMATIC CONTROL VALVE
}

Phase 1 of this CRDA project rigorously confirmed the superior energy efficiency of AeroValve's innovative pneumatic valve technology over conventional technology.

\subsection{BACKGROUND}

Pneumatic systems are pervasive in manufacturing. In general, the efficiency of pneumatics is under $10 \%$. A great deal of the energy loss is associated with the control valves that direct the motion of the pistons. For a conventional pneumatic system, the piston or motor can be controlled in one of two discrete positions. To hold force, full system pressure (generally 60 to $100 \mathrm{psi}$ ) is held against the piston. To move from one position to the other, the control valve vents the piston pressure to atmosphere while it redirects the supply pressure to the other side of the piston. The product of the pressure and displaced volume that is vented to atmosphere is lost energy. AeroValve has developed a revolutionary new pneumatic piston that redirects some of the lost energy back into the piston, significantly increasing efficiency. The objective of this project was to conduct an independent evaluation of the valve performance and efficiency.

\subsection{TECHNICAL RESULTS}

This evaluation confirms that the AeroValve valves are as energy efficient as stated, in almost all cases analyzed. Comparisons were made against a commercial Festo valve with the same manifold mounting configuration and intended application range (Fi. 1). Measuring air consumption per work completed, the AeroValve was as much as $85 \%$ better than the Festo valve under some conditions, though absolute performance of both the Festo valve and the AeroValve varied considerably with the chosen test parameters. 


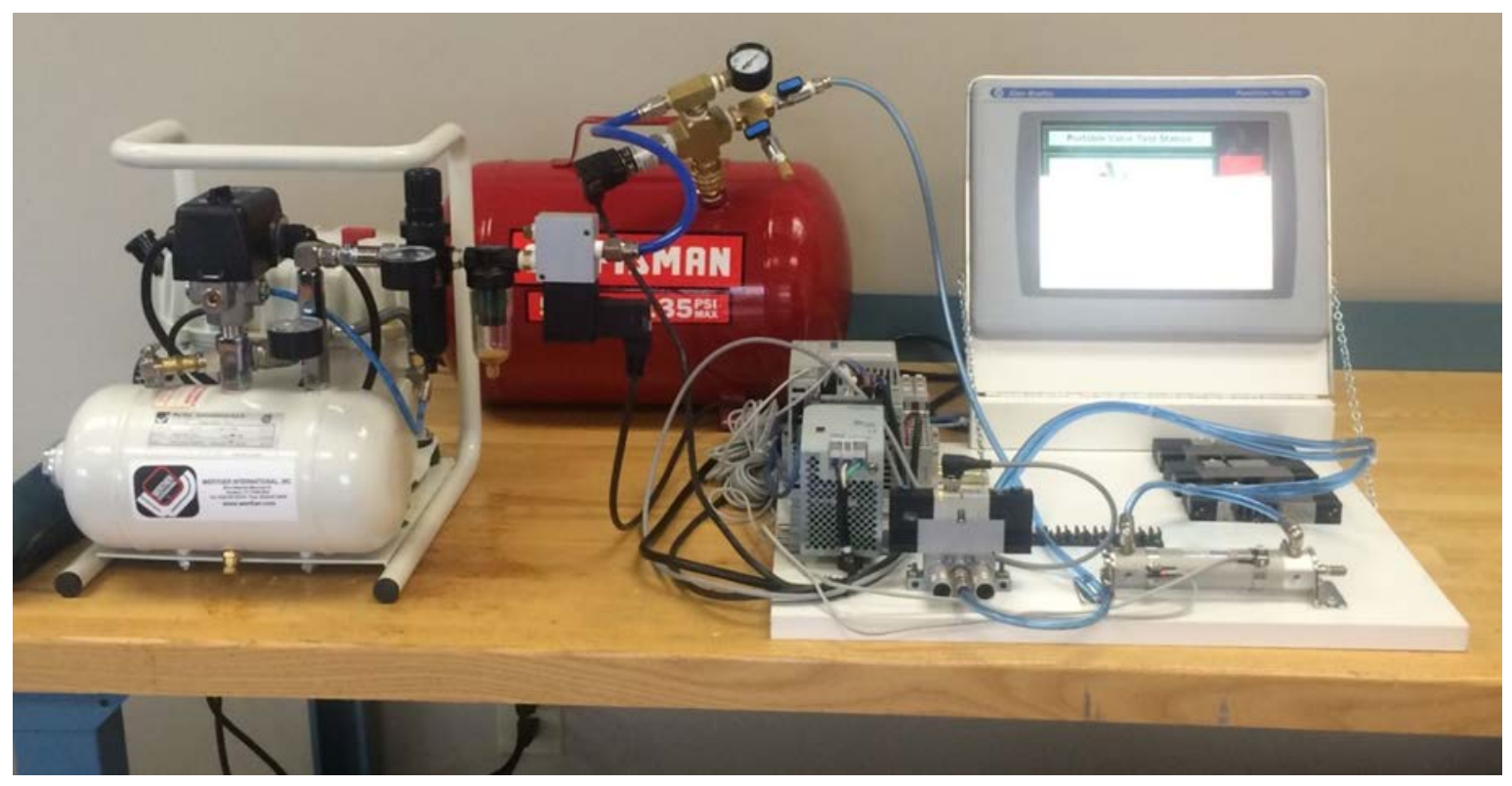

Fig. 1. AeroValve-supplied test bed.

\subsubsection{Line Length Comparison}

Besides the energy efficiency performance validation, ORNL conducted the first AeroValve tests on the effects of line length on valve performance. It was thought that long pneumatic lines may store additional energy that could help valve performance. This effect was not seen, possibly due to the restriction posed by the small diameter supply tubing used in these applications. It appears that valve efficiency improves as line length decreases for both the Festo valve and the AeroValve valves, although the threshold where line length matters was different for each brand of valve.

\subsubsection{Process Decay}

Pressure decay tests measured how much work could be completed with each valve by setting a start and stop pressure and then cycling the tested valves back and forth until the specified amount of air had been expended. AeroValve had previously tested their valves with a line (loop) length of six feet with a stated efficiency advantage over traditional valves such as the Festo of approximately 25 $30 \%$. It was found that this advantage, though always in the AeroValve favor, varied greatly by line length, supply pressure, and delay constant, and the results became more nonlinear as tubing length became shorter. In some cases this efficiency advantage is more than $80 \%$ (Fig. 2). In general both Festo and AeroValve perform better at shorter line lengths. 


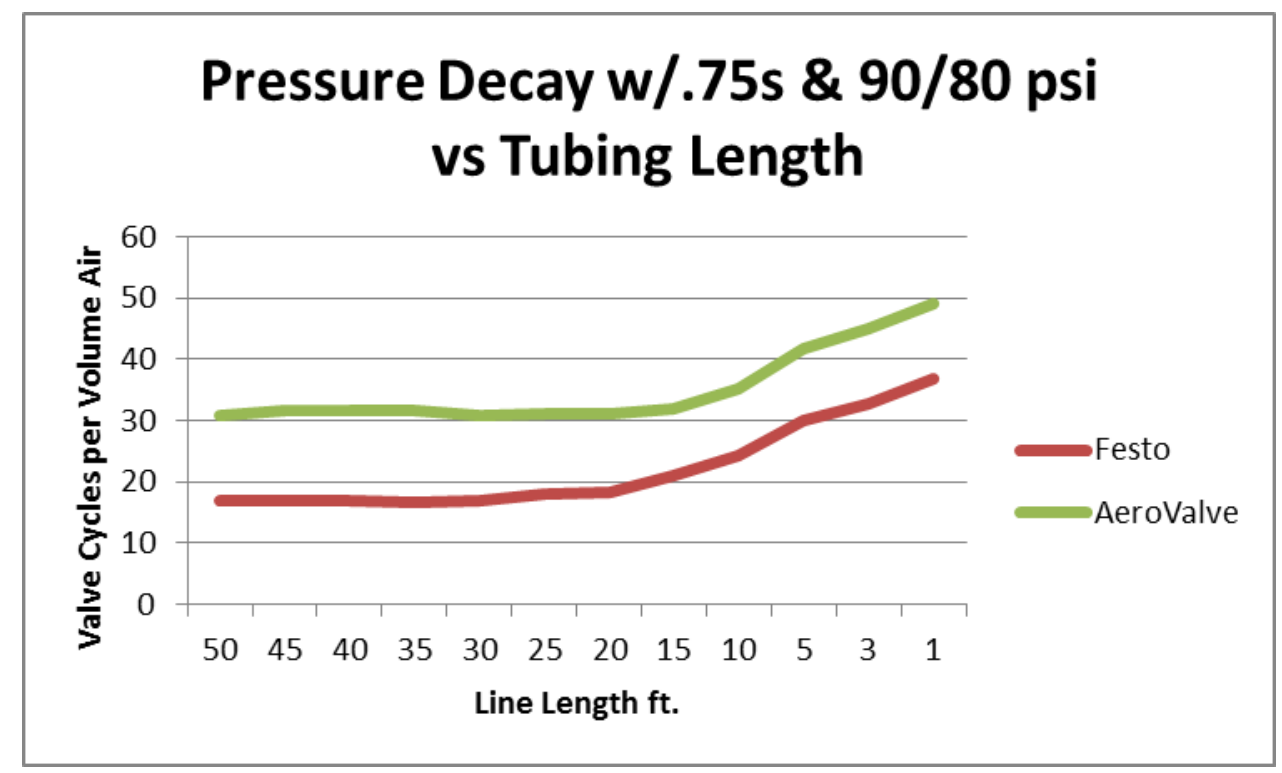

Fig. 2. Pressure decay with .75 s \& $90 / 80$ psi vs. tubing length.

It appears that AeroValve efficiency is higher for lower supply pressures when the delay constant is short (Fig. 3). When the delay constant is long, Festo and AeroValve performance tend to converge as line length gets longer.

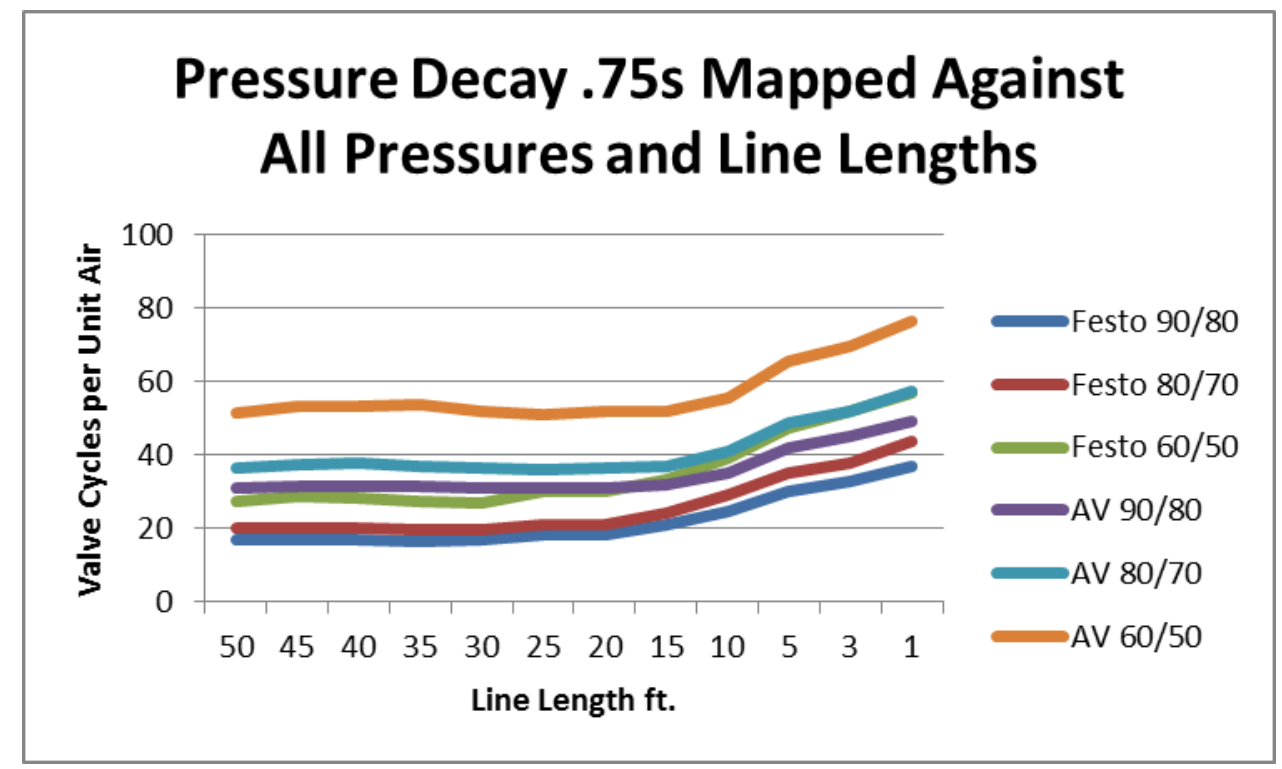

Fig. 3. Pressure decay .75s mapped against all pressures and line lengths.

An increase in the delay time constant from .75s to 1.00 s to $1.5 \mathrm{~s}$ decreased the efficiency of the valves for longer line length (Fig. 4). However as line length became shorter, performance converged to approximately the same points for any delay time. Festo valve convergence happened at approximately $25 \mathrm{ft}$. line length; AeroValve convergence happened at approximately $10 \mathrm{ft}$. line length. 


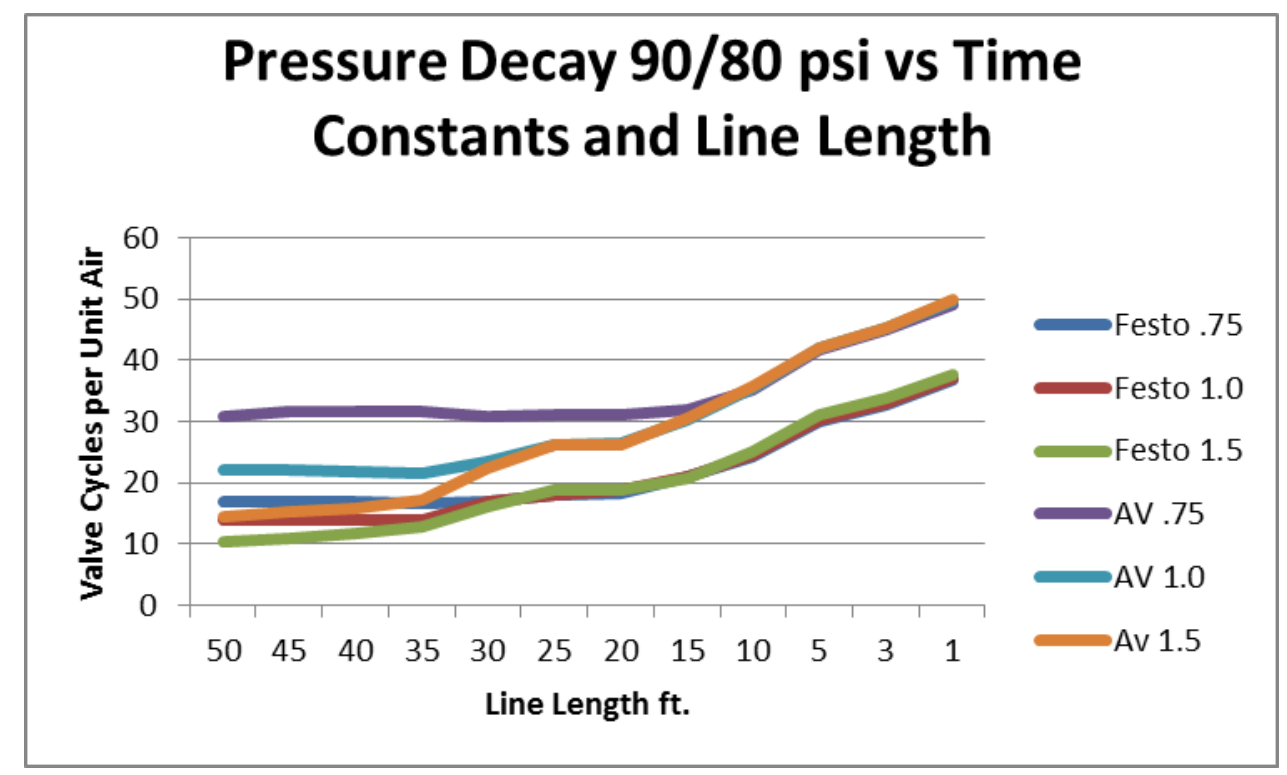

Fig. 4. Pressure decay with $90 / 80$ psi vs. time constants and line length.

The AeroValve design appears to be better than the Festo in efficiency for long line lengths and short delay time constants. When the line length is long and the delay constant is long, AeroValve advantage over the Festo is at its minimum, but it still exists. Both AeroValve and Festo perform best at the shortest possible line lengths.

\subsubsection{Lickety Split}

Lickety Split tests were designed to measure comparative actuation time of the Festo and AeroValve valves. While the AeroValve design provides a gain in efficiency, the design also causes slower actuation than the Festo valve. AeroValve had previously conducted this test only at the six foot line length. The AeroValve style valve is slower than a standard commercial valve. Both valves improved (were quicker) as supply length decreased; however the difference between the AeroValve and the Festo/commercial valve also widened as supply line length decreased. For example the difference was only $30 \%$ at $50 \mathrm{ft}$. line length, but it was more than $100 \%$ at extremely short line lengths. Since the AeroValve's intended target market is for applications where economy of operations is more important that speed of operation, this is not seen as an issue (Fig. 5). 


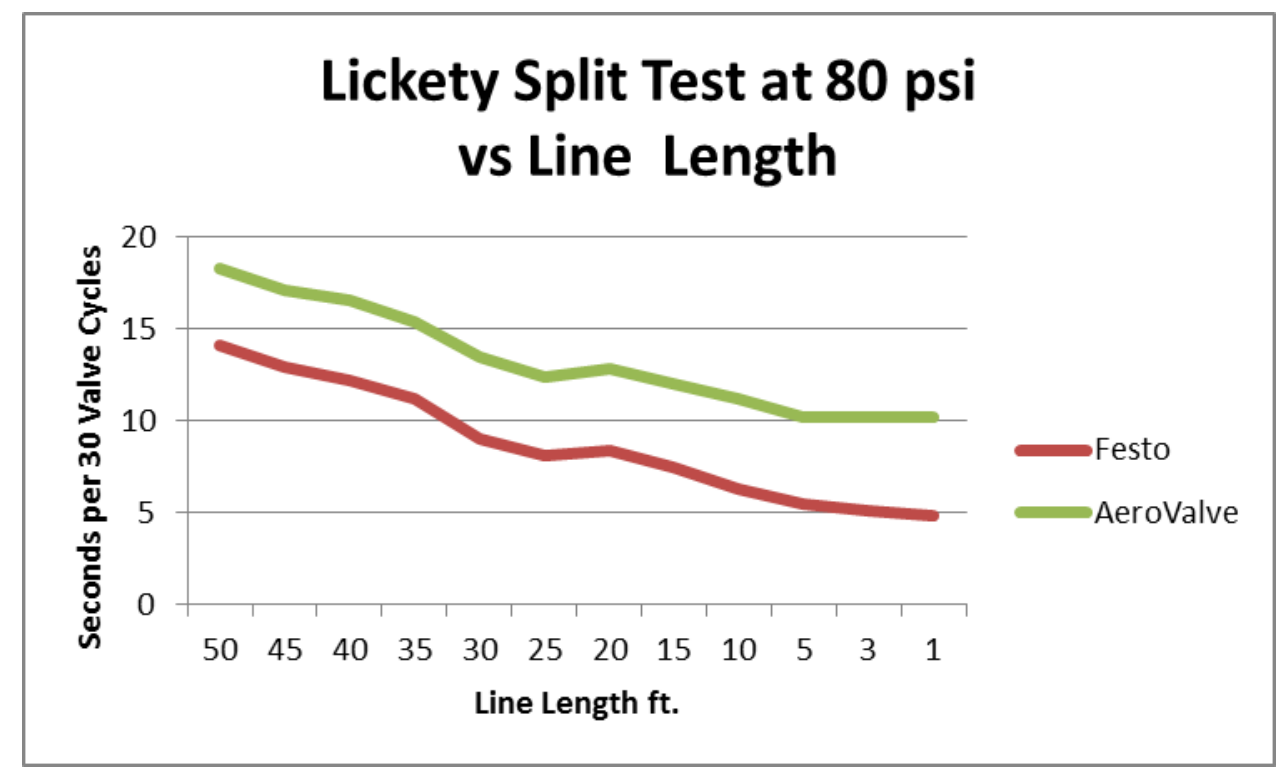

Fig. 5. Lickety split test at 80 psi vs. line length.

\subsubsection{Sound Level Comparison}

A limited test using a calibrated sound level meter was completed on sound level produced by the valves during actuation. Sound level is an important measure of efficiency as well as ergonomics. Typical pneumatic systems have significantly higher sound levels and impact operator safety. Typical sound testing according to ISO3744 involves a highly controlled (quiet) special environment with an array of microphones connected to a data acquisition system. Equipment and facilities for ISO3744 testing were not available; however a comparative (relative, not absolute) test was devised using a calibrated industrial hygiene grade $\mathrm{dB}$ meter in the quietest room available during off hours. Three test runs were completed for each of the four valves: Festo and AeroValve E1, E2, and E3. The test run was the AeroValve pressure decay test with settings of max/min pressure of 90/80psi and a delay time of 1.00s. There did not appear to be an appreciable statistical difference between the Festo and the AeroValve. However, further testing according to industry standards may reveal a slight difference between the two valve types.

Table 1. Sound level comparison between Festo and AeroValve

\begin{tabular}{|l|l|l|l|l|}
\hline Valve & Test 1 & Test 2 & Test 3 & Average \\
\hline Festo & 92.3 & 92.3 & 91.8 & 92.1 \\
\hline AV E1 & 91.6 & 92.2 & 92.3 & 92.2 \\
\hline AV E2 & 91.7 & 91.7 & 91.5 & 91.6 \\
\hline AV E3 & 91.7 & 91.7 & 91.6 & 91.7 \\
\hline
\end{tabular}

\subsubsection{Load Test Comparison}

A load test was also conducted using constant force springs of different spring constants. As load increased, the efficiency of the Festo valve was flat as expected; however the AeroValve efficiency increased with load and was substantially more efficient than the Festo at all loads tested. Fig. 6. 


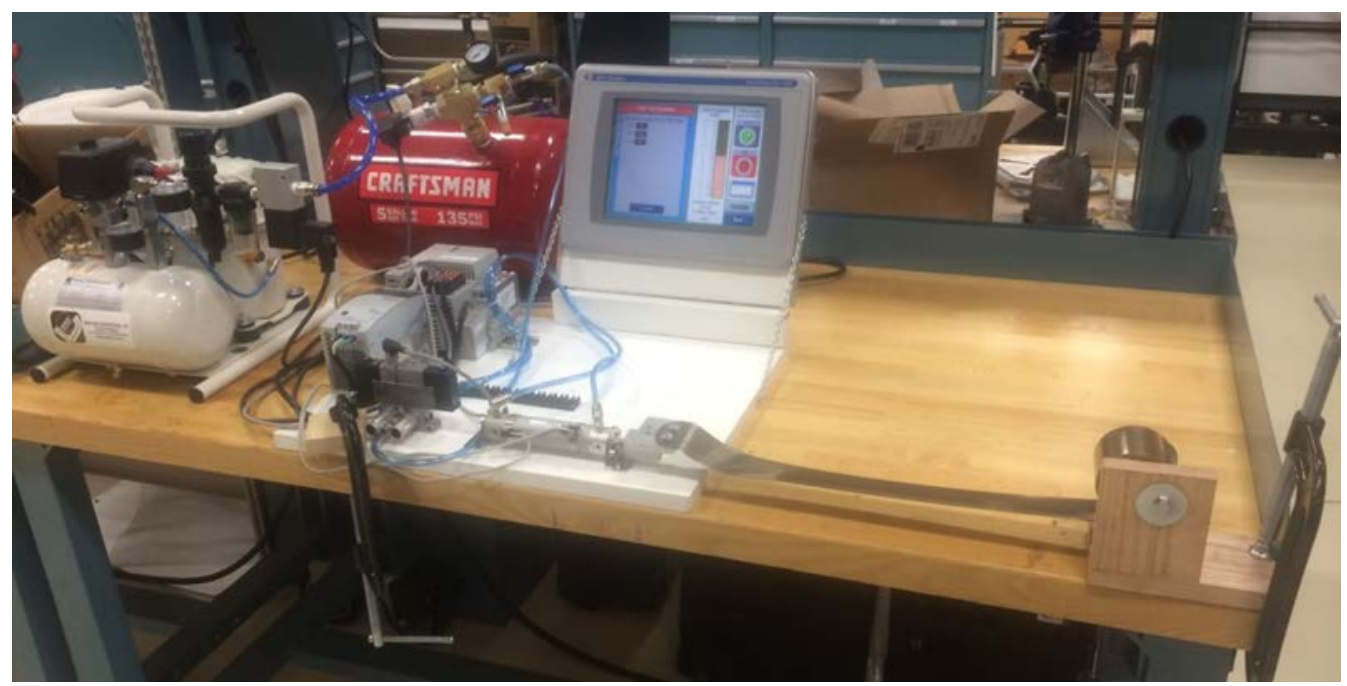

Fig. 6. Load testing with constant force springs.

The AeroVavles performed substantially better under load with respect to efficiency than the Festo valve. It should also be noted that the AeroValve improved performance under load for the forces tested. The data collected is shown in Table 2. For the particular line length tested, the average AeroValve advantage was $42 \%$ at zero force and $75 \%$ at $40 / 9$ lbs. force. The Festo valve is flat (constant) across force applied by design.

Table 2. Lickety split test at 80 psi vs. line length.

\begin{tabular}{|c|c|c|c|c|}
\hline Force in lbs & Festo & AV E-1 & AV E-2 & AV E-3 \\
\hline 0 & 29.3 & 42.3 & 41 & 41.3 \\
\hline 24.8 & 29.3 & 50.7 & 49 & 46.7 \\
\hline 40.9 & 29.7 & 54 & 52 & 50.3 \\
\hline
\end{tabular}

\subsection{IMPACTS}

The experimental data collected in this MDF technical collaboration project support the AeroValve claim of greatly reduced air consumption and energy efficiency improvements, while maintaining load carrying capacity. In limited testing, there was no statistically observable difference in audible sound levels produced by either Festo or AeroValve valves, supporting the energy efficiency measurements. A load test was also conducted using constant force springs of different spring constants. As load increased, the efficiency of the Festo valve was flat as expected; however the AeroValve efficiency increased with load and was substantially more efficient than the Festo at all loads tested. However, the AeroValve valve is slower than a standard commercial valve. Since the AeroValve's intended target market is for applications where economy of operations is more important that speed of operation, this is not seen as an issue.

Further work on this project would address advanced manufacturing processes for the valve. Activities will focus on the feasibility of using metal additive manufacturing for the creation of tooling for injection molding the valve housing part and using carbon fiber reinforced polymers for the main valve components.

\subsection{CONCLUSIONS}

The evaluation of the AeroValve valves concludes that the valves performed as well as AeroValve stated, or better, in almost all cases analyzed where efficiency is concerned. Comparisons were made 
against a commercial Festo valve with the same manifold mounting configuration and intended application range. Measuring air consumption per work completed, the AeroValve was as much as 85\% better than the Festo valve under some conditions, though absolute performance of both the Festo valve and the AeroValve varied considerably with the chosen test parameters. However the AeroValve was always more efficient than the Festo valve for air consumed per work completed for a given set of test conditions.

Besides performance validation, ORNL conducted the first AeroValve tests on the effects of line length on valve performance. It was thought that long pneumatic lines may store additional energy that could help valve performance. This effect was not seen, possibly due to the restriction posed by the small diameter supply tubing used in these applications. It appears that valve efficiency improves as line length decreases for both the Festo valve and the AeroValve valves although the threshold where line length matters was different for each style of valve. 


\section{AEROVALVE LLC BACKGROUND}

AeroValve LLC is a pneumatic valve company with an innovative new technology that addresses a big need in the market - energy reduction. AeroValve is developing a pneumatic solenoid valve that uses recycled compressed air as a supplemental energy source for its mechanical motion. AeroValve's disruptive innovation provides a unique opportunity to achieve significant product differentiation within this highly competitive mature market. The technology can be applied to approximately $60 \%$ of existing directional control valves, reduces the energy cost to end users by reducing compressed air requirements by more than $20 \%$. This innovative technology has been developed as a plug and play replacement for existing valve applications, requiring no changes by the end users. 